\title{
A New Hybrid Algorithm for a System of Mixed Equilibrium Problems, Fixed Point Problems for Nonexpansive Semigroup, and Variational Inclusion Problem
}

\author{
Thanyarat Jitpeera and Poom Kumam \\ Department of Mathematics, Faculty of Science, King Mongkut's University of \\ Technology Thonburi (KMUTT), Bangmod, Bangkok 10140, Thailand \\ Correspondence should be addressed to Poom Kumam, poom.kum@kmutt.ac.th \\ Received 14 December 2010; Accepted 15 January 2011 \\ Academic Editor: Jen Chih Yao
}

Copyright (C) 2011 T. Jitpeera and P. Kumam. This is an open access article distributed under the Creative Commons Attribution License, which permits unrestricted use, distribution, and reproduction in any medium, provided the original work is properly cited.

\begin{abstract}
The purpose of this paper is to consider a shrinking projection method for finding the common element of the set of common fixed points for nonexpansive semigroups, the set of common fixed points for an infinite family of a $\xi$-strict pseudocontraction, the set of solutions of a system of mixed equilibrium problems, and the set of solutions of the variational inclusion problem. Strong convergence of the sequences generated by the proposed iterative scheme is obtained. The results presented in this paper extend and improve some well-known results in the literature.
\end{abstract}

\section{Introduction}

Throughout this paper, we assume that $H$ be a real Hilbert space with inner product $\langle\cdot, \cdot\rangle$ and norm $\|\cdot\|$, and let $C$ be a nonempty closed convex subset of $H$. We denote weak convergence and strong convergence by notations $\rightarrow$ and $\rightarrow$, respectively. Let $\mathfrak{I}=\left\{F_{k}\right\}_{k \in \Gamma}$ be a countable family of bifunctions from $C \times C$ to $R$, where $R$ is the set of real numbers and $\Gamma$ is an arbitrary index set. Let $\varphi: C \rightarrow \mathcal{R} \cup\{+\infty\}$ be a proper extended real-valued function. The system of mixed equilibrium problems is to find $x \in C$ such that

$$
F_{k}(x, y)+\varphi(y) \geq \varphi(x), \quad \forall k \in \Gamma, \forall y \in C
$$

The set of solutions of (1.1) is denoted by $\operatorname{SMEP}\left(F_{k}, \varphi\right)$, that is,

$$
\operatorname{SMEP}\left(F_{k}, \varphi\right)=\left\{x \in C: F_{k}(x, y)+\varphi(y) \geq \varphi(x), \forall k \in \Gamma, \forall y \in C\right\} .
$$


If $\Gamma$ is a singleton, the problem (1.1) reduces to find the following mixed equilibrium problem (see also the work of Flores-Bazán in [1]). For finding $x \in C$ such that,

$$
F(x, y)+\varphi(y) \geq \varphi(x), \quad \forall y \in C
$$

the set of solutions of (1.3) is denoted by $\operatorname{MEP}(F, \varphi)$. Combettes and Hirstoaga [2] introduced the following system of equilibrium problems. For finding $x \in C$ such that,

$$
F_{k}(x, y) \geq 0, \quad \forall k \in \Gamma, \forall y \in C
$$

the set of solutions of (1.4) is denoted by $\operatorname{SEP}(\mathfrak{I})$, that is,

$$
\operatorname{SEP}(\mathfrak{I})=\left\{x \in C: F_{k}(x, y) \geq 0, \forall k \in \Gamma, \forall y \in C\right\}
$$

If $\Gamma$ is a singleton, the problem (1.4) becomes the following equilibrium problem. For finding $x \in C$ such that

$$
F(x, y) \geq 0, \quad \forall y \in C
$$

The set of solution of (1.6) is denoted by $\operatorname{EP}(F)$.

The equilibrium problem include fixed point problems, optimization problems, variational inequalities problems, Nash equilibrium problems, noncooperative games, economics and the (mixed) equilibrium problems as special cases (see, e.g., [3-8]). Some methods have been proposed to solve the equilibrium problem, see, for instance, [9-17].

Recall that, a mapping $T: C \rightarrow C$ is said to be nonexpansive if

$$
\|T x-T y\| \leq\|x-y\|, \quad \forall x, y \in C
$$

We denote the set of fixed points of $T$ by $F(T)$, that is $F(T)=\{x \in C: x=T x\}$.

Definition 1.1. A family $\mathcal{S}=\{S(s): 0 \leq s \leq \infty\}$ of mappings of $C$ into itself is called a nonexpansive semigroup on $C$ if it satisfies the following conditions:

(1) $S(0) x=x$, for all $x \in C$;

(2) $S(s+t)=S(s) S(t)$, for all $s, t \geq 0$;

(3) $\|S(s) x-S(s) y\| \leq\|x-y\|$, for all $x, y \in C$ and $s \geq 0$;

(4) for all $x \in C, s \mapsto S(s) x$ is continuous.

We denoted by $F(S)$ the set of all common fixed points of $\mathcal{S}=\{S(s): s \geq 0\}$, that is, $F(\mathcal{S})=\bigcap_{s \geq 0} F(S(s))$. It is know that $F(\mathcal{S})$ is closed and convex.

Let $B: H \rightarrow H$ be a single-valued nonlinear mapping and $M: H \rightarrow 2^{H}$ be a setvalued mapping. The variational inclusion problem is to find $\widehat{x} \in H$ such that

$$
\theta \in B(\widehat{x})+M(\widehat{x}),
$$


where $\theta$ is the zero vecter in $H$. The set of solutions of problem (1.8) is denoted by $I(B, M)$. A set-valued mapping $M: H \rightarrow 2^{H}$ is called monotone if for all $x, y \in H, f \in M(x)$ and $g \in M(y)$ imply $\langle x-y, f-g\rangle \geq 0$. A monotone mapping $M$ is maximal if its graph $G(M):=$ $\{(f, x) \in H \times H: f \in M(x)\}$ of $M$ is not properly contained in the graph of any other monotone mapping. It is known that a monotone mapping $M$ is maximal if and only if for $(x, f) \in H \times H,\langle x-y, f-g\rangle \geq 0$ for all $(y, g) \in G(M)$ imply $f \in M(x)$.

Definition 1.2. A mapping $B: C \rightarrow H$ is said to be a $k$-Lipschitz continous if there exists a constant $k>0$ such that

$$
\|B x-B y\| \leq k\|x-y\|, \quad \forall x, y \in C
$$

Definition 1.3. A mapping $B: C \rightarrow H$ is said to be a $\beta$-inverse-strongly monotone if there exists a constant $\beta>0$ with the property

$$
\langle B x-B y, x-y\rangle \geq \beta\|B x-B y\|^{2}, \quad \forall x, y \in C .
$$

Remark 1.4. It is obvious that any $\beta$-inverse-strongly monotone mappings $B$ is monotone and $1 / \beta$-Lipschitz continuous. It is easy to see that for any $\lambda$ constant is in $(0,2 \beta]$, then the mapping $I-\lambda B$ is nonexpansive, where $I$ is the identity mapping on $H$.

Definition 1.5. Let $\eta: C \times C \rightarrow H$ is called Lipschitz continuous, if there exists a constant $L>0$ such that

$$
\|\eta(x, y)\| \leq L\|x-y\|, \quad \forall x, y \in C
$$

Let $\mathcal{K}: C \rightarrow R$ be a differentiable functional on a convex set $C$, which is called:

(1) $\eta$-convex $[18]$ if

$$
\mathcal{K}(y)-\mathcal{K}(x) \geq\left\langle\mathcal{K}^{\prime}(x), \eta(y, x)\right\rangle, \quad \forall x, y \in C,
$$

where $\mathcal{K}^{\prime}(x)$ is the Fréchet derivative of $\mathcal{K}$ at $x$;

(2) $\eta$-strongly convex [19] if there exists a constant $\sigma>0$ such that

$$
\mathcal{K}(y)-\mathcal{K}(x)-\left\langle\mathcal{K}^{\prime}(x), \eta(y, x)\right\rangle \geq \frac{\sigma}{2}\|x-y\|^{2}, \quad \forall x, y \in C
$$

In particular, if $\eta(x, y)=x-y$ for all $x, y \in C$, then $\mathcal{K}$ is said to be strongly convex.

Definition 1.6. Let $M: H \rightarrow 2^{H}$ be a set-valued maximal monotone mapping, then the singlevalued mapping $J_{M, \lambda}: H \rightarrow H$ defined by

$$
J_{M, \lambda}(\widehat{x})=(I+\lambda M)^{-1}(\widehat{x}), \quad \widehat{x} \in H
$$

is called the resolvent operator associated with $M$, where $\lambda$ is any positive number and $I$ is the identity mapping. The following characterizes the resolvent operator. 
(R1) The resolvent operator $J_{M, \lambda}$ is single-valued and nonexpansive for all $\lambda>0$, that is,

$$
\left\|J_{M, \lambda}(x)-J_{M, \lambda}(y)\right\| \leq\|x-y\|, \quad \forall x, y \in H, \forall \lambda>0 .
$$

(R2) The resolvent operator $J_{M, \lambda}$ is 1-inverse-strongly monotone; see [20], that is,

$$
\left\|J_{M, \lambda}(x)-J_{M, \lambda}(y)\right\|^{2} \leq\left\langle x-y, J_{M, \lambda}(x)-J_{M, \lambda}(y)\right\rangle, \quad \forall x, y \in H
$$

(R3) The solution of problem (1.8) is a fixed point of the operator $J_{M, \lambda}(I-\lambda B)$ for all $\lambda>0$; see also [21], that is,

$$
I(B, M)=F\left(J_{M, \lambda}(I-\lambda B)\right), \quad \forall \lambda>0 .
$$

(R4) If $0<\lambda \leq 2 \beta$, then the mapping $J_{M, \lambda}(I-\lambda B): H \rightarrow H$ is nonexpansive.

(R5) $I(B, M)$ is closed and convex.

In 2007, Takahashi et al. [22] proved the following strong convergence theorem for a nonexpansive mapping by using the shrinking projection method in mathematical programming. For $C_{1}=C$ and $x_{1}=P_{C_{1}} x_{0}$, they define a sequence $\left\{x_{n}\right\}$ as follows:

$$
\begin{gathered}
y_{n}=\alpha_{n} x_{n}+\left(1-\alpha_{n}\right) T x_{n}, \\
C_{n+1}=\left\{z \in C_{n}:\left\|y_{n}-z\right\| \leq\left\|x_{n}-z\right\|\right\}, \\
x_{n+1}=P_{C_{n+1}} x_{0}, \quad \forall n \geq 0,
\end{gathered}
$$

where $0 \leq \alpha_{n}<a<1$. They proved that the sequence $\left\{x_{n}\right\}$ generated by (1.18) converges weakly to $z \in F(T)$, where $z=P_{F(T)} x_{0}$.

In 2008, S. Takahashi and W. Takahashi [23] introduced the following iterative scheme for finding a common element of the set of solution of generalized equilibrium problem and the set of fixed points of a nonexpansive mapping in a Hilbert space. They proved the strong convergence theorems under certain appropriate conditions imposed on parameters. Next, Zhang et al. [24] introduced the following new iterative scheme for finding a common element of the set of solution to the problem (1.8) and the set of fixed points of a nonexpansive mapping in a real Hilbert space. Starting with an arbitrary $x_{1}=x \in H$, define a sequence $\left\{x_{n}\right\}$ by

$$
\begin{gathered}
y_{n}=J_{M, \lambda}\left(x_{n}-\lambda B x_{n}\right), \\
x_{n+1}=\alpha_{n} x+\left(1-\alpha_{n}\right) T y_{n}, \quad \forall n \geq 1,
\end{gathered}
$$

where $J_{M, \lambda}=(I+\lambda M)^{-1}$ is the resolvent operator associated with $M$ and a positive number $\lambda$ and $\left\{\alpha_{n}\right\}$ is a sequence in the interval $[0,1]$. Peng et al. [25] introduced the iterative scheme by the viscosity approximation method for finding a common element of the set of solutions 
to the problem (1.8), the set of solutions of an equilibrium problem, and the set of fixed points of a nonexpansive mapping in a Hilbert space.

In 2009, Saeidi [26] introduced a more general iterative algorithm for finding a common element of the set of solution for a system of equilibrium problems and the set of common fixed points for a finite family of nonexpansive mappings and a nonexpansive semigroup. In 2010, Katchang and Kumam [27] obtained a strong convergence theorem for finding a common element of the set of fixed points of a family of finitely nonexpansive mappings, the set of solutions of a mixed equilibrium problem and the set of solutions of a variational inclusion problem for an inverse-strongly monotone mapping. Let $W_{n}$ be $W$-mapping (defined by (2.8)), $f$ be a contraction mapping and $A, B$ be inverse-strongly monotone mappings. Let $J_{M, \lambda}=(I+\lambda M)^{-1}$ be the resolvent operator associated with $M$ and a positive number $\lambda$. Starting with arbitrary initial $x_{1} \in H$, defined a sequence $\left\{x_{n}\right\}$ by

$$
\begin{aligned}
& F\left(u_{n}, y\right)+\varphi(y)-\varphi\left(u_{n}\right)+\frac{1}{r_{n}}\left\langle y-u_{n}, u_{n}-x_{n}\right\rangle \geq 0, \quad \forall y \in C, \\
& y_{n}=J_{M, \lambda}\left(u_{n}-\lambda A u_{n}\right), \\
& v_{n}=J_{M, \lambda}\left(y_{n}-\lambda A y_{n}\right), \\
& x_{n+1}=\alpha_{n} \gamma f\left(x_{n}\right)+\beta_{n} x_{n}+\left(\left(1-\beta_{n}\right) I-\alpha_{n} B\right) W_{n} v_{n}, \quad \forall n \geq 1 .
\end{aligned}
$$

They proved that under certain appropriate conditions imposed on $\left\{\alpha_{n}\right\},\left\{\beta_{n}\right\}$, and $\left\{r_{n}\right\}$, the sequence $\left\{x_{n}\right\}$ generated by (1.20) converges strongly to $p \in \Omega:=\bigcap_{i=1}^{\infty} F\left(S_{i}\right) \cap I(A, M) \cap$ $\operatorname{MEP}(F, \varphi)$, where $p=P_{\Omega}(I-B+\gamma f) p$. Later, Kumam et al. [28] proved a strongly convergence theorem of the iterative sequence generated by the shrinking projection method for finding a common element of the set of solutions of generalized mixed equilibrium problems, the set of fixed points of a finite family of quasinonexpansive mappings, and the set of solutions of variational inclusion problems.

Liu et al. [29] introduced a hybrid iterative scheme for finding a common element of the set of solutions of mixed equilibrium problems, the set of common fixed points for nonexpansive semigroup and the set of solution of quasivariational inclusions with multivalued maximal monotone mappings and inverse-strongly monotone mappings. Recently, Jitpeera and Kumam [30] considered a shrinking projection method of finding the common element of the set of common fixed points for a finite family of a $\xi$-strict pseudocontraction, the set of solutions of a systems of equilibrium problems and the set of solutions of variational inclusions. Then, they proved strong convergence theorems of the iterative sequence generated by the shrinking projection method under some suitable conditions in a real Hilbert space. Very recently, Hao [18] introduced a general iterative method for finding a common element of solution set of quasi variational inclusion problems and of the common fixed point set of an infinite family of nonexpansive mappings.

In this paper, motivated and inspired by the previously mentioned results, we introduce an iterative scheme by the shrinking projection method for finding the common element of the set of common fixed points for nonexpansive semigroups, the set of common fixed points for an infinite family of a $\xi$-strict pseudocontraction, the set of solutions of a systems of mixed equilibrium problems and the set of solutions of the variational inclusions problem. Then, we prove a strong convergence theorem of the iterative sequence generated by the shrinking projection method under some suitable conditions. The results obtained in this paper extend and improve several recent results in this area. 


\section{Preliminaries}

Let $H$ be a real Hilbert space and $C$ be a nonempty closed convex subset of $H$. Recall that the (nearest point) projection $P_{C}$ from $H$ onto $C$ assigns to each $x \in H$ the unique point in $P_{C} x \in C$ satisfying the property $\left\|x-P_{C} x\right\|=\min _{y \in C}\|x-y\|$.

The following characterizes the projection $P_{C}$. We recall some lemmas which will be needed in the rest of this paper.

Lemma 2.1. For a given $z \in H, u \in C, u=P_{C} z \Leftrightarrow\langle u-z, v-u\rangle \geq 0$, for all $v \in C$.

It is well known that $P_{C}$ is a firmly nonexpansive mapping of $H$ onto $C$ and satisfies

$$
\left\|P_{C} x-P_{C} y\right\|^{2} \leq\left\langle P_{C} x-P_{C} y, x-y\right\rangle, \quad \forall x, y \in H
$$

Moreover, $P_{C} x$ is characterized by the following properties: $P_{C} x \in C$ and for all $x \in H, y \in C$,

$$
\left\langle x-P_{C} x, y-P_{C} x\right\rangle \leq 0
$$

Lemma 2.2 (see [20]). Let $M: H \rightarrow 2^{H}$ be a maximal monotone mapping and let $B: H \rightarrow H$ be a Lipshitz continuous mapping. Then the mapping $L=M+B: H \rightarrow 2^{H}$ is a maximal monotone mapping.

Lemma 2.3 (see [31]). Let $C$ be a closed convex subset of $H$. Let $\left\{x_{n}\right\}$ be a bounded sequence in $H$. Assume that

(1) the weak $\omega$-limit set $\omega_{w}\left(x_{n}\right) \subset C$,

(2) for each $z \in C, \lim _{n \rightarrow \infty}\left\|x_{n}-z\right\|$ exists.

Then $\left\{x_{n}\right\}$ is weakly convergent to a point in C.

Lemma 2.4 (see [32]). Each Hilbert space $H$ satisfies Opial's condition, that is, for any sequence $\left\{x_{n}\right\} \subset H$ with $x_{n} \rightarrow x$, the inequality $\lim \inf _{n \rightarrow \infty}\left\|x_{n}-x\right\|<\lim _{\inf _{n \rightarrow \infty}}\left\|x_{n}-y\right\|$, hold for each $y \in H$ with $y \neq x$.

Lemma 2.5 (see [33]). Each Hilbert space H, satisfies the Kadec-Klee property, that is, for any sequence $\left\{x_{n}\right\}$ with $x_{n} \rightarrow x$ and $\left\|x_{n}\right\| \rightarrow\|x\|$ together imply $\left\|x_{n}-x\right\| \rightarrow 0$.

For solving the system of mixed equilibrium problem, let us assume that function $F_{k}$ : $C \times C \rightarrow R, k=1,2, \ldots, N$ satisfies the following conditions:

(H1) $F_{k}$ is monotone, that is, $F_{k}(x, y)+F_{k}(y, x) \leq 0$, for all $x, y \in C$;

(H2) for each fixed $y \in C, x \mapsto F_{k}(x, y)$ is convex and upper semicontinuous;

(H3) for each fixed $x \in C, y \mapsto F_{k}(x, y)$ is convex.

Lemma 2.6 (see [34]). Let $C$ be a nonempty closed convex subset of a real Hilbert space $H$ and let $\varphi$ be a lower semicontinuous and convex functional from $C$ to $R$. Let $F$ be a bifunction from $C \times C$ to $R$ 
satisfying (H1)-(H3). Assume that

(i) $\eta: C \times C \rightarrow H$ is $k$ Lipschitz continuous with constant $k>0$ such that;

(a) $\eta(x, y)+\eta(y, x)=0$, for all $x, y \in C$,

(b) $\eta(\cdot, \cdot)$ is affine in the first variable,

(c) for each fixed $x \in C, y \mapsto \eta(x, y)$ is sequentially continuous from the weak topology to the weak topology,

(ii) $\mathcal{K}: C \rightarrow \mathcal{R}$ is $\eta$-strongly convex with constant $\sigma>0$ and its derivative $\mathcal{K}^{\prime}$ is sequentially continuous from the weak topology to the strong topology;

(iii) for each $x \in C$, there exist a bounded subset $D_{x} \subset C$ and $z_{x} \in C$ such that for any $y \in C \backslash D_{x}$,

$$
F\left(y, z_{x}\right)+\varphi\left(z_{x}\right)-\varphi(y)+\frac{1}{r}\left\langle\mathcal{K}^{\prime}(y)-\mathcal{K}^{\prime}(x), \eta\left(z_{x}, y\right)\right\rangle<0 .
$$

For given $r>0$, Let $K_{r}^{F}: C \rightarrow C$ be the mapping defined by:

$$
K_{r}^{F}(x)=\left\{y \in C: F(y, z)+\varphi(z)-\varphi(y)+\frac{1}{r}\left\langle\mathcal{K}^{\prime}(y)-\mathcal{K}^{\prime}(x), \eta(z, y)\right\rangle \geq 0, \forall z \in C\right\}
$$

for all $x \in C$. Then the following hold

(1) $K_{r}^{F}$ is single-valued;

(2) $K_{r}^{F}$ is nonexpansive if $\mathcal{K}^{\prime}$ is Lipschitz continuous with constant $v>0$ such that $\sigma \geq k v$;

(3) $F\left(K_{r}^{F}\right)=\operatorname{MEP}(F, \varphi)$;

(4) $\operatorname{MEP}(F, \varphi)$ is closed and convex.

Lemma 2.7 (see [35]). Let $V: C \rightarrow H$ be a $\xi$-strict pseudocontraction, then

(1) the fixed point set $F(V)$ of $V$ is closed convex so that the projection $P_{F(V)}$ is well defined;

(2) define a mapping $T: C \rightarrow H$ by

$$
T x=t x+(1-t) V x, \quad \forall x \in C .
$$

If $t \in[\xi, 1)$, then $T$ is a nonexpansive mapping such that $F(V)=F(T)$.

A family of mappings $\left\{V_{i}: C \rightarrow H\right\}_{i=1}^{\infty}$ is called a family of uniformly $\xi$-strict pseudocontractions, if there exists a constant $\xi \in[0,1)$ such that

$$
\left\|V_{i} x-V_{i} y\right\|^{2} \leq\|x-y\|^{2}+\xi\left\|\left(I-V_{i}\right) x-\left(I-V_{i}\right) y\right\|^{2}, \quad \forall x, y \in C, \forall i \geq 1 .
$$


Let $\left\{V_{i}: C \rightarrow C\right\}_{i=1}^{\infty}$ be a countable family of uniformly $\xi$-strict pseudocontractions. Let $\left\{T_{i}: C \rightarrow C\right\}_{i=1}^{\infty}$ be the sequence of nonexpansive mappings defined by (2.5), that is,

$$
T_{i} x=t x+(1-t) V_{i} x, \quad \forall x \in C, \forall i \geq 1, t \in[\xi, 1)
$$

Let $\left\{T_{i}\right\}$ be a sequence of nonexpansive mappings of $C$ into itself defined by (2.7) and let $\left\{\mu_{i}\right\}$ be a sequence of nonnegative numbers in $[0,1]$. For each $n \geq 1$, define a mapping $W_{n}$ of $C$ into itself as follows:

$$
\begin{aligned}
U_{n, n+1} & =I, \\
U_{n, n} & =\mu_{n} T_{n} U_{n, n+1}+\left(1-\mu_{n}\right) I, \\
U_{n, n-1} & =\mu_{n-1} T_{n-1} U_{n, n}+\left(1-\mu_{n-1}\right) I, \\
& \vdots \\
U_{n, k} & =\mu_{k} T_{k} U_{n, k+1}+\left(1-\mu_{k}\right) I, \\
U_{n, k-1} & =\mu_{k-1} T_{k-1} U_{n, k}+\left(1-\mu_{k-1}\right) I, \\
& \vdots \\
U_{n, 2} & =\mu_{2} T_{2} U_{n, 3}+\left(1-\mu_{2}\right) I, \\
W_{n}=U_{n, 1} & =\mu_{1} T_{1} U_{n, 2}+\left(1-\mu_{1}\right) I .
\end{aligned}
$$

Such a mapping $W_{n}$ is nonexpansive from $C$ to $C$ and it is called the $W$-mapping generated by $T_{1}, T_{2}, \ldots, T_{n}$ and $\mu_{1}, \mu_{2}, \ldots, \mu_{n}$. For each $n, k \in \mathbb{N}$, let the mapping $U_{n, k}$ be defined by (2.8). Then we can have the following crucial conclusions concerning $W_{n}$.

Lemma 2.8 (see [36]). Let $C$ be a nonempty closed convex subset of a real Hilbert space $H$. Let $T_{1}, T_{2}, \ldots$ be nonexpansive mappings of $C$ into itself such that $\bigcap_{i=1}^{\infty} F\left(T_{i}\right)$ is nonempty, let $\mu_{1}, \mu_{2}, \ldots$ be real numbers such that $0 \leq \mu_{i} \leq b<1$ for every $i \geq 1$. Then, for every $x \in C$ and $k \in \mathbb{N}$, $\lim _{n \rightarrow \infty} U_{n, k} x$ exists.

Using this lemma, one can define a mapping $U_{\infty, k}$ and $W: C \rightarrow C$ as follows $U_{\infty, k} x=$ $\lim _{n \rightarrow \infty} U_{n, k} x$ and

$$
W x:=\lim _{n \rightarrow \infty} W_{n} x=\lim _{n \rightarrow \infty} U_{n, 1} x, \quad \forall x \in C .
$$

Such a mapping $W$ is called the $W$-mapping. Since $W_{n}$ is nonexpansive and $F(W)=\bigcap_{i=1}^{\infty} F\left(T_{i}\right)$, $W: C \rightarrow C$ is also nonexpansive. Indeed, observe that for each $x, y \in C$ such that

$$
\|W x-W y\|=\lim _{n \rightarrow \infty}\left\|W_{n} x-W_{n} y\right\| \leq\|x-y\|
$$


Lemma 2.9 (see [36]). Let $C$ be a nonempty closed convex subset of a Hilbert space $H,\left\{T_{i}: C \rightarrow C\right\}$ be a countable family of nonexpansive mappings with $\bigcap_{i=1}^{\infty} F\left(T_{i}\right) \neq \emptyset,\left\{\mu_{i}\right\}$ be a real sequence such that $0<\mu_{i} \leq b<1$, for all $i \geq 1$. Then $F(W)=\bigcap_{i=1}^{\infty} F\left(T_{i}\right)$.

Lemma 2.10 (see [37]). Let $C$ be a nonempty closed convex subset of a Hilbert space $H,\left\{T_{i}: C \rightarrow\right.$ C $\}$ be a countable family of nonexpansive mappings with $\bigcap_{i=1}^{\infty} F\left(T_{i}\right) \neq \emptyset,\left\{\mu_{i}\right\}$ be a real sequence such that $0<\mu_{i} \leq b<1$, for all $i \geq 1$. If $D$ is any bounded subset of $C$, then

$$
\limsup _{n \rightarrow \infty}\left\|W x-W_{n} x\right\|=0
$$

Lemma 2.11 (see [38]). Let $C$ be a nonempty bounded closed convex subset of a Hilbert space $H$ and let $\mathcal{S}=\{S(s): 0 \leq s<\infty\}$ be a nonexpansive semigroup on $C$, then for any $h \geq 0$,

$$
\limsup _{t \rightarrow \infty}\left\|\frac{1}{t} \int_{0}^{t} T(s) x d s-T(h)\left(\frac{1}{t} \int_{0}^{t} T(s) x d s\right)\right\|=0 .
$$

Lemma 2.12 (see [39]). Let $C$ be a nonempty bounded closed convex subset of $H,\left\{x_{n}\right\}$ be a sequence in $C$ and $S=\{S(s): 0 \leq s<\infty\}$ be a nonexpansive semigroup on $C$. If the following conditions are satisfied:

(1) $x_{n} \rightarrow z$;

(2) $\limsup \sup _{s \rightarrow \infty} \lim \sup _{n \rightarrow \infty}\left\|S(s) x_{n}-x_{n}\right\|=0$, then $z \in F(\mathcal{S})$.

\section{Main Results}

In this section, we will introduce an iterative scheme by using a shrinking projection method for finding the common element of the set of common fixed points for nonexpansive semigroups, the set of common fixed points for an infinite family of $\xi$-strict pseudocontraction, the set of solutions of a systems of mixed equilibrium problems and the set of solutions of the variational inclusions problem in a real Hilbert space.

Theorem 3.1. Let $C$ be a nonempty closed convex subset of a real Hilbert space $H$, let $\left\{F_{k}: C \times\right.$ $C \rightarrow R, k=1,2, \ldots, N\}$ be a finite family of mixed equilibrium functions satisfying conditions (H1)-(H3). Let $\mathcal{S}=\{S(s): 0 \leq s<\infty\}$ be a nonexpansive semigroup on $C$ and let $\left\{t_{n}\right\}$ be a positive real divergent sequence. Let $\left\{V_{i}: C \rightarrow C\right\}_{i=1}^{\infty}$ be a countable family of uniformly $\xi$-strict pseudocontractions, $\left\{T_{i}: C \rightarrow C\right\}_{i=1}^{\infty}$ be the countable family of nonexpansive mappings defined by $T_{i} x=t x+(1-t) V_{i} x$, for all $x \in C$, for all $i \geq 1, t \in[\xi, 1), W_{n}$ be the $W$-mapping defined by (2.8) and $W$ be a mapping defined by (2.9) with $F(W) \neq \emptyset$. Let $A, B: C \rightarrow H$ be $\gamma, \beta$-inverse-strongly monotone mappings and $M_{1}, M_{2}: H \rightarrow 2^{H}$ be maximal monotone mappings such that

$$
\Theta:=F(\mathcal{S}) \cap F(W) \cap\left(\bigcap_{k=1}^{N} \operatorname{SMEP}\left(F_{k}\right)\right) \cap I\left(A, M_{1}\right) \cap I\left(B, M_{2}\right) \neq \emptyset
$$


Let $r_{k}>0, k=1,2, \ldots, N$, which are constants. Let $\left\{x_{n}\right\},\left\{y_{n}\right\},\left\{v_{n}\right\},\left\{z_{n}\right\}$, and $\left\{u_{n}\right\}$ be sequences generated by $x_{0} \in C, C_{1}=C, x_{1}=P_{C_{1}} x_{0}, u_{n} \in C$ and

$$
\begin{gathered}
x_{0}=x \in C \text { chosen arbitrarily, } \\
u_{n}=K_{r_{N, n}}^{F_{N}} K_{r_{N-1, n}}^{F_{N-1}} K_{r_{N-2, n}}^{F_{N-2}} \cdots K_{r_{2, n}}^{F_{2}} K_{r_{1, n}}^{F_{1}} x_{n}, \\
y_{n}=J_{M_{2}, \delta_{n}}\left(u_{n}-\delta_{n} B u_{n}\right), \\
v_{n}=J_{M_{1}, \lambda_{n}}\left(y_{n}-\lambda_{n} A y_{n}\right), \\
C_{n+1}=\alpha_{n} v_{n}+\left(1-\alpha_{n}\right) \frac{1}{t_{n}} \int_{0}^{t_{n}} S(s) W_{n} v_{n} d s, \\
\left.z \in C_{n}:\left\|z_{n}-z\right\|^{2} \leq\left\|x_{n}-z\right\|^{2}-\alpha_{n}\left(1-\alpha_{n}\right)\left\|v_{n}-\frac{1}{t_{n}} \int_{0}^{t_{n}} S(s) W_{n} v_{n} d s\right\|^{2}\right\}, \\
x_{n+1}=P_{C_{n+1}} x_{0}, \quad n \in \mathbb{N},
\end{gathered}
$$

where $K_{r_{k}}^{F_{k}}: C \rightarrow C, k=1,2, \ldots, N$ is the mapping defined by (2.4) and $\left\{\alpha_{n}\right\}$ be a sequence in $(0,1)$ for all $n \in \mathbb{N}$. Assume the following conditions are satisfied:

(C1) $\eta_{k}: C \times C \rightarrow H$ is $L_{k}$-Lipschitz continuous with constant $k=1,2, \ldots, N$ such that

(a) $\eta_{k}(x, y)+\eta_{k}(y, x)=0$, for all $x, y \in C$,

(b) $x \mapsto \eta_{k}(x, y)$ is affine,

(c) for each fixed $y \in C, y \mapsto \eta_{k}(x, y)$ is sequentially continuous from the weak topology to the weak topology;

(C2) $\mathcal{K}_{k}: C \rightarrow \mathcal{R}$ is $\eta_{k}$-strongly convex with constant $\sigma_{k}>0$ and its derivative $\mathcal{K}_{k}^{\prime}$ is not only sequentially continuous from the weak topology to the strong topology but also Lipschitz continuous with a Lipschitz constant $v_{k}>0$ such that $\sigma_{k}>L_{k} v_{k}$;

(C3) for each $k \in\{1,2, \ldots, N\}$ and for all $x \in C$, there exist a bounded subset $D_{x} \subset C$ and $z_{x} \in C$ such that for any $y \in C \backslash D_{x}$,

$$
F_{k}\left(y, z_{x}\right)+\varphi\left(z_{x}\right)-\varphi(y)+\frac{1}{r_{k}}\left\langle\mathcal{K}^{\prime}(y)-\mathcal{K}^{\prime}(x), \eta\left(z_{x}, y\right)\right\rangle<0,
$$

(C4) $\left\{\alpha_{n}\right\} \subset[c, d]$, for some $c, d \in(\xi, 1)$;

(C5) $\left\{\lambda_{n}\right\} \subset\left[a_{1}, b_{1}\right]$, for some $a_{1}, b_{1} \in(0,2 \gamma]$;

(C6) $\left\{\delta_{n}\right\} \subset\left[a_{2}, b_{2}\right]$, for some $a_{2}, b_{2} \in(0,2 \beta]$;

(C7) $\lim \inf _{n \rightarrow \infty} r_{k, n}>0$, for each $k \in 1,2,3, \ldots, N$.

Then, $\left\{x_{n}\right\}$ and $\left\{u_{n}\right\}$ converge strongly to $z=P_{\Theta} x_{0}$. 
Proof. Pick any $p \in \Theta$. Taking $\Im_{n}^{k}=K_{r_{k, n}}^{F_{k}} K_{r_{k-1, n}}^{F_{k-1}} K_{r_{k-2, n}}^{F_{k-2}} \cdots K_{r_{2, n}}^{F_{2}} K_{r_{1, n}}^{F_{1}}$ for $k \in\{1,2,3, \ldots, N\}$ and $\mathfrak{I}_{n}^{0}=I$ for all $n \in \mathbb{N}$. From the definition of $K_{r_{k, n}}^{F_{k}}$ is nonexpansive for each $k=1,2,3, \ldots, N$, then $\mathfrak{I}_{n}^{k}$ also and $p=\mathfrak{I}_{r_{k, n}}^{F_{k}} p$, we note that $u_{n}=\mathfrak{I}_{n}^{N} x_{n}$. If follows that

$$
\left\|u_{n}-p\right\|=\left\|\mathfrak{I}_{n}^{N} x_{n}-\Im_{n}^{N} p\right\| \leq\left\|x_{n}-p\right\|
$$

Next, we will divide the proof into eight steps.

Step 1. We first show by induction that $\Theta \subset C_{n}$ for each $n \geq 1$.

Taking $p \in \Theta$, we get that $p=J_{M_{1}, \lambda_{k}}\left(p-\lambda_{k} A p\right)=J_{M_{2}, \delta_{k}}\left(p-\delta_{k} B p\right)$. Since $J_{M_{1}, \lambda_{k}}, J_{M_{2}, \delta_{k}}$ are nonexpansive. From the assumption, we see that $\Theta \subset C=C_{1}$. Suppose $\Theta \subset C_{k}$ for some $k \geq 1$. For any $p \in \Theta=C_{k}$, we have

$$
\begin{aligned}
\left\|v_{k}-p\right\| & =\left\|J_{M_{1}, \lambda_{k}}\left(y_{k}-\lambda_{k} A y_{k}\right)-J_{M_{1}, \lambda_{k}}\left(p-\lambda_{k} A p\right)\right\| \\
& \leq\left\|\left(y_{k}-\lambda_{k} A y_{k}\right)-\left(p-\lambda_{k} A p\right)\right\| \\
& \leq\left\|\left(I-\lambda_{k} A\right) y_{k}-\left(I-\lambda_{k} A\right) p\right\| \\
& \leq\left\|y_{k}-p\right\|, \\
\left\|y_{k}-p\right\| & =\left\|J_{M_{2}, \delta_{k}}\left(u_{k}-\delta_{k} B u_{k}\right)-J_{M_{2}, \delta_{k}}\left(p-\delta_{k} B p\right)\right\| \\
& \leq\left\|\left(u_{k}-\delta_{k} B u_{k}\right)-\left(p-\delta_{k} B p\right)\right\| \\
& \leq\left\|u_{k}-p\right\| \\
& \leq\left\|x_{k}-p\right\|,
\end{aligned}
$$

which yields

$$
\begin{aligned}
\left\|z_{k}-p\right\|^{2}= & \left\|\alpha_{k}\left(v_{k}-p\right)+\left(1-\alpha_{k}\right)\left(\frac{1}{t_{k}} \int_{0}^{t_{k}} S(s) W_{k} v_{k} d s-p\right)\right\|^{2} \\
\leq & \alpha_{k}\left\|v_{k}-p\right\|^{2}+\left(1-\alpha_{k}\right)\left\|\frac{1}{t_{k}} \int_{0}^{t_{k}} S(s) W_{k} v_{k} d s-p\right\|^{2} \\
& -\alpha_{k}\left(1-\alpha_{k}\right)\left\|v_{k}-\frac{1}{t_{k}} \int_{0}^{t_{k}} S(s) W_{k} v_{k} d s\right\|^{2} \\
\leq & \alpha_{k}\left\|v_{k}-p\right\|^{2}+\left(1-\alpha_{k}\right)\left\|v_{k}-p\right\|^{2}-\alpha_{k}\left(1-\alpha_{k}\right)\left\|v_{k}-\frac{1}{t_{k}} \int_{0}^{t_{k}} S(s) W_{k} v_{k} d s\right\|^{2} \\
\leq & \left\|v_{k}-p\right\|^{2}-\alpha_{k}\left(1-\alpha_{k}\right)\left\|v_{k}-\frac{1}{t_{k}} \int_{0}^{t_{k}} S(s) W_{k} v_{k} d s\right\|^{2} .
\end{aligned}
$$


Applying (3.5) and (3.6), we get

$$
\left\|z_{k}-p\right\|^{2} \leq\left\|x_{k}-p\right\|^{2}-\alpha_{k}\left(1-\alpha_{k}\right)\left\|v_{k}-\frac{1}{t_{k}} \int_{0}^{t_{k}} S(s) W_{k} v_{k} d s\right\|^{2} .
$$

Hence $p \in C_{k+1}$. This implies that $\Theta \subset C_{n}$ for each $n \geq 1$.

Step 2. Next, we show that $\left\{x_{n}\right\}$ is well defined and $C_{n}$ is closed and convex for any $n \in \mathbb{N}$.

It is obvious that $C_{1}=C$ is closed and convex. Suppose that $C_{k}$ is closed and convex for some $k \geq 1$. Now, we show that $C_{k+1}$ is closed and convex for some $k$. For any $p \in C_{k}$, we obtain

$$
\left\|z_{k}-p\right\|^{2} \leq\left\|x_{k}-p\right\|^{2}
$$

is equivalent to

$$
\left\|z_{k}-x_{k}\right\|^{2}+2\left\langle z_{k}-x_{k}, x_{k}-p\right\rangle \leq 0
$$

Thus $C_{k+1}$ is closed and convex. Then, $C_{n}$ is closed and convex for any $n \in \mathbb{N}$. This implies that $\left\{x_{n}\right\}$ is well-defined.

Step 3. Next, we show that $\left\{x_{n}\right\}$ is bounded and $\lim _{n \rightarrow \infty}\left\|x_{n}-x_{0}\right\|$ exists. From $x_{n}=P_{C_{n}} x_{0}$, we have

$$
\left\langle x_{0}-x_{n}, x_{n}-y\right\rangle \geq 0
$$

for each $y \in C_{n}$. Using $\Theta \subset C_{n}$, we also have

$$
\left\langle x_{0}-x_{n}, x_{n}-p\right\rangle \geq 0, \quad \forall p \in \Theta, n \in \mathbb{N} .
$$

So, for $p \in \Theta$, we observe that

$$
\begin{aligned}
0 & \leq\left\langle x_{0}-x_{n}, x_{n}-p\right\rangle \\
& =\left\langle x_{0}-x_{n}, x_{n}-x_{0}+x_{0}-p\right\rangle \\
& =-\left\langle x_{0}-x_{n}, x_{0}-x_{n}\right\rangle+\left\langle x_{0}-x_{n}, x_{0}-p\right\rangle \\
& \leq-\left\|x_{0}-x_{n}\right\|^{2}+\left\|x_{0}-x_{n}\right\|\left\|x_{0}-p\right\| .
\end{aligned}
$$

This implies that

$$
\left\|x_{0}-x_{n}\right\| \leq\left\|x_{0}-p\right\|, \quad \forall p \in \Theta, n \in \mathbb{N} .
$$


Hence, we get $\left\{x_{n}\right\}$ is bounded. It follows by (3.5)-(3.7), that $\left\{v_{n}\right\},\left\{y_{n}\right\}$, and $\left\{W_{n} v_{n}\right\}$ are also bounded. From $x_{n}=P_{C_{n}} x_{0}$, and $x_{n+1}=P_{C_{n+1}} x_{0} \in C_{n+1} \subset C_{n}$, we obtain

$$
\left\langle x_{0}-x_{n}, x_{n}-x_{n+1}\right\rangle \geq 0
$$

It follows that, we have for each $n \in \mathbb{N}$

$$
\begin{aligned}
0 & \leq\left\langle x_{0}-x_{n}, x_{n}-x_{n+1}\right\rangle \\
& =\left\langle x_{0}-x_{n}, x_{n}-x_{0}+x_{0}-x_{n+1}\right\rangle \\
& =-\left\langle x_{0}-x_{n}, x_{0}-x_{n}\right\rangle+\left\langle x_{0}-x_{n}, x_{0}-x_{n+1}\right\rangle \\
& \leq-\left\|x_{0}-x_{n}\right\|^{2}+\left\|x_{0}-x_{n}\right\|\left\|x_{0}-x_{n+1}\right\| .
\end{aligned}
$$

It follows that

$$
\left\|x_{0}-x_{n}\right\| \leq\left\|x_{0}-x_{n+1}\right\|
$$

Thus, since the sequence $\left\{\left\|x_{n}-x_{0}\right\|\right\}$ is a bounded and nondecreasing sequence, so $\lim _{n \rightarrow \infty}\left\|x_{n}-x_{0}\right\|$ exists, that is

$$
m=\lim _{n \rightarrow \infty}\left\|x_{n}-x_{0}\right\|
$$

Step 4. Next, we show that $\lim _{n \rightarrow \infty}\left\|x_{n+1}-x_{n}\right\|=0$ and $\lim _{n \rightarrow \infty}\left\|x_{n}-z_{n}\right\|=0$.

Applying (3.15), we get

$$
\begin{aligned}
\left\|x_{n}-x_{n+1}\right\|^{2} & =\left\|x_{n}-x_{0}+x_{0}-x_{n+1}\right\|^{2} \\
& =\left\|x_{n}-x_{0}\right\|^{2}+2\left\langle x_{n}-x_{0}, x_{0}-x_{n+1}\right\rangle+\left\|x_{0}-x_{n+1}\right\|^{2} \\
& =\left\|x_{n}-x_{0}\right\|^{2}+2\left\langle x_{n}-x_{0}, x_{0}-x_{n}+x_{n}-x_{n+1}\right\rangle+\left\|x_{0}-x_{n+1}\right\|^{2} \\
& =\left\|x_{n}-x_{0}\right\|^{2}-2\left\langle x_{n}-x_{0}, x_{n}-x_{0}\right\rangle+2\left\langle x_{n}-x_{0}, x_{n}-x_{n+1}\right\rangle+\left\|x_{0}-x_{n+1}\right\|^{2} \\
& =-\left\|x_{n}-x_{0}\right\|^{2}+2\left\langle x_{n}-x_{0}, x_{n}-x_{n+1}\right\rangle+\left\|x_{0}-x_{n+1}\right\|^{2} \\
& \leq-\left\|x_{n}-x_{0}\right\|^{2}+\left\|x_{0}-x_{n+1}\right\|^{2} .
\end{aligned}
$$

Thus, by (3.18), we obtain

$$
\lim _{n \rightarrow \infty}\left\|x_{n}-x_{n+1}\right\|=0
$$


On the other hand, from $x_{n+1}=P_{C_{n+1}} x_{0} \in C_{n+1} \subset C_{n}$, which implies that

$$
\left\|x_{n+1}-z_{n}\right\| \leq\left\|x_{n+1}-x_{n}\right\|
$$

It follows by (3.21), we also have

$$
\left\|z_{n}-x_{n}\right\| \leq\left\|z_{n}-x_{n+1}\right\|+\left\|x_{n+1}-x_{n}\right\| \leq 2\left\|x_{n}-x_{n+1}\right\| .
$$

By (3.20), we obtain

$$
\lim _{n \rightarrow \infty}\left\|x_{n}-z_{n}\right\|=0
$$

Step 5. Next, we show that

$$
\lim _{n \rightarrow \infty}\left\|\mathfrak{I}_{n}^{k} x_{n}-\Im_{n}^{k-1} x_{n}\right\|=0
$$

for every $k \in\{1,2,3, \ldots, N\}$. Indeed, for $p \in \Theta$, note that $K_{r_{k, n}}^{F_{k}}$ is the firmly nonexpansie, so we have

$$
\begin{aligned}
\left\|\mathfrak{I}_{n}^{k} x_{n}-\mathfrak{I}_{n}^{k} p\right\|^{2} & =\left\|K_{r_{k, n}}^{F_{k}} \mathfrak{I}_{n}^{k-1} x_{n}-K_{r_{k, n}}^{F_{k}} p\right\|^{2} \\
& \leq\left\langle\mathfrak{I}_{n}^{k} x_{n}-p, \mathfrak{I}_{n}^{k-1} x_{n}-p\right\rangle \\
& =\frac{1}{2}\left\{\left\|\Im_{n}^{k} x_{n}-p\right\|^{2}+\left\|\Im_{n}^{k-1} x_{n}-p\right\|^{2}-\left\|\Im_{n}^{k} x_{n}-\Im_{n}^{k-1} x_{n}\right\|^{2}\right\} .
\end{aligned}
$$

Thus, we get

$$
\left\|\mathfrak{I}_{n}^{k} x_{n}-\mathfrak{I}_{n}^{k} p\right\|^{2} \leq\left\|\mathfrak{\Im}_{n}^{k-1} x_{n}-p\right\|^{2}-\left\|\Im_{n}^{k} x_{n}-\mathfrak{I}_{n}^{k-1} x_{n}\right\|^{2}
$$

It follows that

$$
\begin{aligned}
\left\|u_{n}-p\right\|^{2} & \leq\left\|\Im_{n}^{k} x_{n}-\Im_{n}^{k} p\right\|^{2} \\
& \leq\left\|\Im_{n}^{k-1} x_{n}-p\right\|^{2}-\left\|\Im_{n}^{k} x_{n}-\Im_{n}^{k-1} x_{n}\right\|^{2} \\
& \leq\left\|x_{n}-p\right\|^{2}-\left\|\Im_{n}^{k} x_{n}-\Im_{n}^{k-1} x_{n}\right\|^{2} .
\end{aligned}
$$


By (3.5), (3.6), (3.7), and (3.27), we have for each $k \in\{1,2,3, \ldots, N\}$

$$
\begin{aligned}
\left\|z_{n}-p\right\|^{2} & \leq\left\|v_{n}-p\right\|^{2} \\
& \leq\left\|u_{n}-p\right\|^{2} \\
& \leq\left\|x_{n}-p\right\|^{2}-\left\|\Im_{n}^{k} x_{n}-\Im_{n}^{k-1} x_{n}\right\|^{2} .
\end{aligned}
$$

Consequently, we have

$$
\begin{aligned}
\left\|\mathfrak{I}_{n}^{k} x_{n}-\Im_{n}^{k-1} x_{n}\right\|^{2} & \leq\left\|x_{n}-p\right\|^{2}-\left\|z_{n}-p\right\|^{2} \\
& \leq\left\|x_{n}-z_{n}\right\|\left(\left\|x_{n}-p\right\|+\left\|z_{n}-p\right\|\right) .
\end{aligned}
$$

Equation (3.23) implies that for every $k \in\{1,2,3, \ldots, N\}$

$$
\lim _{n \rightarrow \infty}\left\|\mathfrak{I}_{n}^{k} x_{n}-\mathfrak{I}_{n}^{k-1} x_{n}\right\|=0
$$

Step 6. Next, we show that $\lim _{n \rightarrow \infty}\left\|y_{n}-v_{n}\right\|=0$ and $\lim _{n \rightarrow \infty}\left\|\mathcal{K}_{n} W_{n} v_{n}-v_{n}\right\|=0$, where $\boldsymbol{\mathcal { K }}_{n}=\left(1 / t_{n}\right) \int_{0}^{t_{n}} S(s) d s$.

For any given $p \in \Theta, \lambda_{n} \in(0,2 \gamma], \delta_{n} \in(0,2 \beta]$ and $p=J_{M_{1}, \lambda_{n}}\left(p-\lambda_{n} A p\right)=J_{M_{2}, \delta_{n}}(p-$ $\left.\delta_{n} B p\right)$. Since $I-\lambda_{n} A$ and $I-\delta_{n} B$ are nonexpansive, we have

$$
\begin{aligned}
\left\|v_{n}-p\right\|^{2} & =\left\|J_{M_{1}, \lambda_{n}}\left(y_{n}-\lambda_{n} A y_{n}\right)-J_{M_{1}, \lambda_{n}}\left(p-\lambda_{n} A p\right)\right\|^{2} \\
& \leq\left\|\left(y_{n}-\lambda_{n} A y_{n}\right)-\left(p-\lambda_{n} A p\right)\right\|^{2} \\
& =\left\|\left(y_{n}-p\right)-\lambda_{n}\left(A y_{n}-A p\right)\right\|^{2} \\
& \leq\left\|y_{n}-p\right\|^{2}-2 \lambda_{n}\left\langle y_{n}-p, A y_{n}-A p\right\rangle+\lambda_{n}^{2}\left\|A y_{n}-A p\right\|^{2} \\
& \leq\left\|x_{n}-p\right\|^{2}-2 \lambda_{n} \gamma\left\|A y_{n}-A p\right\|^{2}+\lambda_{n}^{2}\left\|A y_{n}-A p\right\|^{2} \\
& \leq\left\|x_{n}-p\right\|^{2}+\lambda_{n}\left(\lambda_{n}-2 \gamma\right)\left\|A y_{n}-A p\right\|^{2} .
\end{aligned}
$$

Similarly, we can show that

$$
\left\|y_{n}-p\right\|^{2} \leq\left\|x_{n}-p\right\|^{2}+\delta_{n}\left(\delta_{n}-2 \beta\right)\left\|B u_{n}-B p\right\|^{2} .
$$


Observe that

$$
\begin{aligned}
\left\|z_{n}-p\right\|^{2}= & \left\|\alpha_{n}\left(v_{n}-p\right)+\left(1-\alpha_{n}\right)\left(\frac{1}{t_{n}} \int_{0}^{t_{n}} S(s) W_{n} v_{n} d s-p\right)\right\|^{2} \\
\leq & \alpha_{n}\left\|v_{n}-p\right\|^{2}+\left(1-\alpha_{n}\right)\left\|\frac{1}{t_{n}} \int_{0}^{t_{n}} S(s) W_{n} v_{n} d s-p\right\|^{2} \\
& -\alpha_{n}\left(1-\alpha_{n}\right)\left\|v_{n}-\frac{1}{t_{n}} \int_{0}^{t_{n}} S(s) W_{n} v_{n} d s\right\|^{2} \\
\leq & \alpha_{n}\left\|v_{n}-p\right\|^{2}+\left(1-\alpha_{n}\right)\left\|\frac{1}{t_{n}} \int_{0}^{t_{n}} S(s) W_{n} v_{n} d s-p\right\|^{2} \\
\leq & \alpha_{n}\left\|x_{n}-p\right\|^{2}+\left(1-\alpha_{n}\right)\left\|v_{n}-p\right\|^{2} .
\end{aligned}
$$

Substituting (3.31) into (3.33) and using conditions (C4) and (C5), we have

$$
\begin{aligned}
\left\|z_{n}-p\right\|^{2} & \leq \alpha_{n}\left\|x_{n}-p\right\|^{2}+\left(1-\alpha_{n}\right)\left\{\left\|x_{n}-p\right\|^{2}+\lambda_{n}\left(\lambda_{n}-2 \gamma\right)\left\|A y_{n}-A p\right\|^{2}\right\} \\
& =\left\|x_{n}-p\right\|^{2}+\left(1-\alpha_{n}\right) \lambda_{n}\left(\lambda_{n}-2 \gamma\right)\left\|A y_{n}-A p\right\|^{2} .
\end{aligned}
$$

It follows that

$$
\begin{aligned}
(1-d) a_{1}\left(2 \gamma-b_{1}\right)\left\|A y_{n}-A p\right\|^{2} & \leq\left(1-\alpha_{n}\right) \lambda_{n}\left(2 \gamma-\lambda_{n}\right)\left\|A y_{n}-A p\right\|^{2} \\
& \leq\left\|x_{n}-p\right\|^{2}-\left\|z_{n}-p\right\|^{2} \\
& \leq\left\|x_{n}-z_{n}\right\|\left(\left\|x_{n}-p\right\|+\left\|z_{n}-p\right\|\right) .
\end{aligned}
$$

By (3.23), we obtain

$$
\lim _{n \rightarrow \infty}\left\|A y_{n}-A p\right\|=0 .
$$


Fixed Point Theory and Applications

Since the resolvent operator $J_{M_{1}, \lambda_{n}}$ is 1-inverse-strongly monotone, we obtain

$$
\begin{aligned}
\left\|v_{n}-p\right\|^{2}= & \left\|J_{M_{1}, \lambda_{n}}\left(y_{n}-\lambda_{n} A y_{n}\right)-J_{M_{1}, \lambda_{n}}\left(p-\lambda_{n} A p\right)\right\|^{2} \\
= & \left\|J_{M_{1}, \lambda_{n}}\left(I-\lambda_{n} A\right) y_{n}-J_{M_{1}, \lambda_{n}}\left(I-\lambda_{n} A\right) p\right\|^{2} \\
\leq & \left\langle\left(I-\lambda_{n} A\right) y_{n}-\left(I-\lambda_{n} A\right) p, v_{n}-p\right\rangle \\
= & \frac{1}{2}\left\{\left\|\left(I-\lambda_{n} A\right) y_{n}-\left(I-\lambda_{n} A\right) p\right\|^{2}+\left\|v_{n}-p\right\|^{2}\right. \\
& \left.\quad-\left\|\left(I-\lambda_{n} A\right) y_{n}-\left(I-\lambda_{n} A\right) p-\left(v_{n}-p\right)\right\|^{2}\right\} \\
\leq & \frac{1}{2}\left\{\left\|y_{n}-p\right\|^{2}+\left\|v_{n}-p\right\|^{2}-\left\|\left(y_{n}-v_{n}\right)-\lambda_{n}\left(A y_{n}-A p\right)\right\|^{2}\right\} \\
\leq & \frac{1}{2}\left\{\left\|x_{n}-p\right\|^{2}+\left\|v_{n}-p\right\|^{2}-\left\|y_{n}-v_{n}\right\|^{2}\right. \\
& \left.\quad-\lambda_{n}^{2}\left\|A y_{n}-A p\right\|^{2}+2 \lambda_{n}\left\langle y_{n}-v_{n}, A y_{n}-A p\right\rangle\right\},
\end{aligned}
$$

which yields

$$
\left\|v_{n}-p\right\|^{2} \leq\left\|x_{n}-p\right\|^{2}-\left\|y_{n}-v_{n}\right\|^{2}+2 \lambda_{n}\left\|y_{n}-v_{n}\right\|\left\|A y_{n}-A p\right\| .
$$

Similarly, we can obtain

$$
\left\|y_{n}-p\right\|^{2} \leq\left\|x_{n}-p\right\|^{2}-\left\|u_{n}-y_{n}\right\|^{2}+2 \delta_{n}\left\|u_{n}-y_{n}\right\|\left\|B u_{n}-B p\right\|
$$

Substituting (3.38) into (3.33), and using condition (C4) and (C5), we have

$$
\begin{aligned}
\left\|z_{n}-p\right\|^{2} & \leq \alpha_{n}\left\|x_{n}-p\right\|^{2}+\left(1-\alpha_{n}\right)\left\|v_{n}-p\right\|^{2} \\
& \leq \alpha_{n}\left\|x_{n}-p\right\|^{2}+\left(1-\alpha_{n}\right)\left\{\left\|x_{n}-p\right\|^{2}-\left\|y_{n}-v_{n}\right\|^{2}+2 \lambda_{n}\left\|y_{n}-v_{n}\right\|\left\|A y_{n}-A p\right\|\right\} \\
& =\left\|x_{n}-p\right\|^{2}-\left(1-\alpha_{n}\right)\left\|y_{n}-v_{n}\right\|^{2}+2\left(1-\alpha_{n}\right) \lambda_{n}\left\|y_{n}-v_{n}\right\|\left\|A y_{n}-A p\right\| .
\end{aligned}
$$

It follows that

$$
\begin{aligned}
\left(1-\alpha_{n}\right)\left\|y_{n}-v_{n}\right\|^{2} & \leq\left\|x_{n}-p\right\|^{2}-\left\|z_{n}-p\right\|^{2}+2\left(1-\alpha_{n}\right) \lambda_{n}\left\|y_{n}-v_{n}\right\|\left\|A y_{n}-A p\right\| \\
& \leq\left\|x_{n}-z_{n}\right\|\left(\left\|x_{n}-p\right\|+\left\|z_{n}-p\right\|\right)+2\left(1-\alpha_{n}\right) \lambda_{n}\left\|y_{n}-v_{n}\right\|\left\|A y_{n}-A p\right\| .
\end{aligned}
$$

By (3.23) and (3.36), we get

$$
\lim _{n \rightarrow \infty}\left\|y_{n}-v_{n}\right\|=0
$$


From (3.8) and (C4), we also have

$$
\begin{aligned}
\alpha_{n}\left(1-\alpha_{n}\right)\left\|v_{n}-\frac{1}{t_{n}} \int_{0}^{t_{n}} S(s) W_{n} v_{n} d s\right\|^{2} & \leq\left\|x_{n}-p\right\|^{2}-\left\|z_{n}-p\right\|^{2} \\
& \leq\left\|x_{n}-z_{n}\right\|\left(\left\|x_{n}-p\right\|+\left\|z_{n}-p\right\|\right) .
\end{aligned}
$$

Since $\mathcal{K}_{n}=\left(1 / t_{n}\right) \int_{0}^{t_{n}} S(s) d s$, we obtain (3.23), we have

$$
\lim _{n \rightarrow \infty}\left\|\mathcal{K}_{n} W_{n} v_{n}-v_{n}\right\|=0
$$

Since $\left\{W_{n} v_{n}\right\}$ is a bounded sequence in $C$, from Lemma 2.11 for all $h \geq 0$, we have

$$
\begin{aligned}
\lim _{n \rightarrow \infty} & \left\|\mathcal{K}_{n} W_{n} v_{n}-S(h) \mathcal{K}_{n} W_{n} v_{n}\right\| \\
& =\lim _{n \rightarrow \infty}\left\|\frac{1}{t_{n}} \int_{0}^{t_{n}} S(s) W_{n} v_{n} d s-S(h)\left(\frac{1}{t_{n}} \int_{0}^{t_{n}} S(s) W_{n} v_{n} d s\right)\right\|=0 .
\end{aligned}
$$

From (3.44) and (3.45), we get

$$
\begin{aligned}
\left\|v_{n}-S(s) v_{n}\right\| & \leq\left\|v_{n}-\mathcal{K}_{n} W_{n} v_{n}\right\|+\left\|\mathcal{K}_{n} W_{n} v_{n}-S(s) \mathcal{K}_{n} W_{n} v_{n}\right\|+\left\|S(s) \mathcal{K}_{n} W_{n} v_{n}-S(s) v_{n}\right\| \\
& \leq 2\left\|v_{n}-\mathcal{K}_{n} W_{n} v_{n}\right\|+\left\|\mathcal{K}_{n} W_{n} v_{n}-S(s) \mathcal{K}_{n} W_{n} v_{n}\right\| .
\end{aligned}
$$

So, we have

$$
\lim _{n \rightarrow \infty}\left\|v_{n}-S(s) v_{n}\right\|=0
$$

Step 7. Next, we show that $q \in \Theta:=F(\mathcal{S}) \cap F(W) \cap\left(\bigcap_{k=1}^{N} \operatorname{SMEP}\left(F_{k}\right)\right) \cap I\left(A, M_{1}\right) \cap I\left(B, M_{2}\right) \neq \emptyset$. Since $\left\{v_{n_{i}}\right\}$ is bounded, there exists a subsequence $\left\{v_{n_{i_{j}}}\right\}$ of $\left\{v_{n_{i}}\right\}$ which converges weakly to $q \in C$. Without loss of generality, we can assume that $v_{n_{i}} \rightarrow q$.

(1) First, we prove that $q \in F(\mathcal{S})$. Indeed, from Lemma 2.12 and (3.47), we get $q \in$ $F(\mathcal{S})$, that is, $q=S(s) q$, for all $s \geq 0$.

(2) We show that $q \in F(W)=\bigcap_{n=1}^{\infty} F\left(W_{n}\right)$, where $F\left(W_{n}\right)=\bigcap_{i=1}^{\infty} F\left(T_{i}\right)$, for all $n \geq 1$ and $F\left(W_{n+1}\right) \subset F\left(W_{n}\right)$. Assume that $q \notin F(W)$, then there exists a positive integer $m$ such that $q \notin F\left(T_{m}\right)$ and so $q \notin \bigcap_{i=1}^{m} F\left(T_{i}\right)$. Hence for any $n \geq m, q \notin \bigcap_{i=1}^{n} F\left(T_{i}\right)=F\left(W_{n}\right)$, that is, $q \neq W_{n} q$. This together with $q=S(s) q$, for all $s \geq 0$ shows $q=S(s) q \neq S(s) W_{n} q$, for all $s \geq 0$, 
therefore we have $q \neq \mathcal{K}_{n} W_{n} q$, for all $n \geq m$. It follows from the Opial's condition and (3.44) that

$$
\begin{aligned}
\liminf _{i \rightarrow \infty}\left\|v_{n_{i}}-q\right\| & <\liminf _{i \rightarrow \infty}\left\|v_{n_{i}}-\mathcal{K}_{n_{i}} W_{n_{i}} q\right\| \\
& \leq \liminf _{i \rightarrow \infty}\left(\left\|v_{n_{i}}-\mathcal{K}_{n_{i}} W_{n_{i}} v_{n_{i}}\right\|+\left\|\mathcal{K}_{n_{i}} W_{n_{i}} v_{n_{i}}-\mathcal{K}_{n_{i}} W_{n_{i}} q\right\|\right) \\
& \leq \liminf _{i \rightarrow \infty}\left\|v_{n_{i}}-q\right\|,
\end{aligned}
$$

which is a contradiction. Thus, we get $q \in F(W)$. we have

(3) We prove that $q \in \bigcap_{k=1}^{N} \operatorname{SMEP}\left(F_{k}, \varphi\right)$. Since $\mathfrak{I}_{n}^{k}=\mathcal{K}_{r_{k}}^{F_{k}}, k=1,2, \ldots, N$ and $u_{n}^{k}=\Im_{n}^{k} x_{n}$,

$$
F_{k}\left(\Im_{n}^{k} x_{n}, x\right)+\varphi(x)-\varphi\left(\Im_{n}^{k} x_{n}\right)+\frac{1}{r_{k}}\left\langle\mathcal{K}^{\prime}\left(\Im_{n}^{k} x_{n}\right)-\mathcal{K}^{\prime}\left(\Im_{n}^{k-1} x_{n}\right), \eta\left(x, \Im_{n}^{k} x_{n}\right)\right\rangle \geq 0, \quad \forall x \in C .
$$

It follows that

$$
\frac{1}{r_{k}}\left\langle\mathcal{K}^{\prime}\left(\mathfrak{I}_{n_{i}}^{k} x_{n_{i}}\right)-\mathcal{K}^{\prime}\left(\mathfrak{I}_{n_{i}}^{k-1} x_{n_{i}}\right), \eta\left(x, \mathfrak{I}_{n_{i}}^{k} x_{n_{i}}\right)\right\rangle \geq-F_{k}\left(\Im_{n_{i}}^{k} x_{n_{i}}, x\right)-\varphi(x)+\varphi\left(\Im_{n_{i}}^{k} x_{n_{i}}\right)
$$

for all $x \in C$. From (3.30) and by conditions (C1)(c) and (C2), we get

$$
\lim _{n_{i} \rightarrow \infty} \frac{1}{r_{k}}\left\langle\mathcal{K}^{\prime}\left(\mathfrak{I}_{n_{i}}^{k} x_{n_{i}}\right)-\mathcal{K}^{\prime}\left(\mathfrak{I}_{n_{i}}^{k-1} x_{n_{i}}\right), \eta\left(x, \mathfrak{I}_{n_{i}}^{k} x_{n_{i}}\right)\right\rangle=0
$$

By the assumption and by condition (H1), we know that the function $\varphi$ and the mapping $x \mapsto\left(-F_{k}(x, y)\right)$ both are convex and lower semicontinuous, hence they are weakly lower semicontinuous.

These together with $\left(\mathcal{K}^{\prime}\left(\mathfrak{I}_{n_{i}}^{k} x_{n_{i}}\right)-\mathcal{K}^{\prime}\left(\Im_{n_{i}}^{k-1} x_{n_{i}}\right)\right) / r_{k} \rightarrow 0$ and $\Im_{n_{i}}^{k} x_{n_{i}} \rightarrow q$, we have

$$
\begin{aligned}
0 & =\liminf _{n_{i} \rightarrow \infty}\left\langle\frac{\mathcal{K}^{\prime}\left(\mathfrak{I}_{n_{i}}^{k} x_{n_{i}}\right)-\mathcal{K}^{\prime}\left(\mathfrak{I}_{n_{i}}^{k-1} x_{n_{i}}\right)}{r_{k}}, \eta\left(x, \Im_{n_{i}}^{k} x_{n_{i}}\right)\right\rangle \\
& \geq \liminf _{n_{i} \rightarrow \infty}\left\{-F_{k}\left(\mathfrak{I}_{n_{i}}^{k} x_{n_{i}}, x\right)-\varphi(x)+\varphi\left(\mathfrak{I}_{n_{i}}^{k} x_{n_{i}}\right)\right\} .
\end{aligned}
$$

Then, we obtain

$$
F_{k}(q, x)+\varphi(x)-\varphi(q) \geq 0, \quad \forall x \in C, \forall k=, 1,2, \ldots, N
$$

Therefore $q \in \bigcap_{k=1}^{N} \operatorname{SMEP}\left(F_{k}, \varphi\right)$.

(4) Lastly, we prove that $q \in I\left(A, M_{1}\right) \cap I\left(B, M_{2}\right)$. 
We observe that $A$ is an $1 / \gamma$-Lipschitz monotone mapping and $D(A)=H$. From Lemma 2.2, we know that $M_{1}+A$ is maximal monotone. Let $(v, g) \in G\left(M_{1}+A\right)$ that is, $g-A v \in M_{1}(v)$. Since $v_{n_{i}}=J_{M_{1}, \lambda_{n_{i}}}\left(y_{n_{i}}-\lambda_{n_{i}} A y_{n_{i}}\right)$, we have

$$
y_{n_{i}}-\lambda_{n_{i}} A y_{n_{i}} \in\left(I+\lambda_{n_{i}} M_{1}\right)\left(v_{n_{i}}\right),
$$

that is,

$$
\frac{1}{\lambda_{n_{i}}}\left(y_{n_{i}}-v_{n_{i}}-\lambda_{n_{i}} A y_{n_{i}}\right) \in M_{1}\left(v_{n_{i}}\right)
$$

By virtue of the maximal monotonicity of $M_{1}+A$, we have

$$
\left\langle v-v_{n_{i}}, g-A v-\frac{1}{\lambda_{n_{i}}}\left(y_{n_{i}}-v_{n_{i}}-\lambda_{n_{i}} A y_{n_{i}}\right)\right\rangle \geq 0
$$

and so

$$
\begin{aligned}
\left\langle v-v_{n_{i}}, g\right\rangle & \geq\left\langle v-v_{n_{i}}, A v+\frac{1}{\lambda_{n_{i}}}\left(y_{n_{i}}-v_{n_{i}}-\lambda_{n_{i}} A y_{n_{i}}\right)\right\rangle \\
& =\left\langle v-v_{n_{i}}, A v-A v_{n_{i}}+A v_{n_{i}}-A y_{n_{i}}+\frac{1}{\lambda_{n_{i}}}\left(y_{n_{i}}-v_{n_{i}}\right)\right\rangle \\
& \geq 0+\left\langle v-v_{n_{i}}, A v_{n_{i}}-A y_{n_{i}}\right\rangle+\left\langle v-v_{n_{i}}, \frac{1}{\lambda_{n_{i}}}\left(y_{n_{i}}-v_{n_{i}}\right)\right\rangle .
\end{aligned}
$$

By (3.42), $v_{n_{i}} \rightarrow q$ and $A$ is inverse-strongly monotone, we obtain that $\lim _{n \rightarrow \infty}\left\|A y_{n}-A v_{n}\right\|=0$ and it follows that

$$
\lim _{n_{i} \rightarrow \infty}\left\langle v-v_{n_{i}}, g\right\rangle=\langle v-q, g\rangle \geq 0
$$

It follows from the maximal monotonicity of $M_{1}+A$ that $\theta \in\left(M_{1}+A\right)(q)$, that is, $q \in I\left(A, M_{1}\right)$. Since $\left\{y_{n_{i}}\right\}$ is bounded, there exists a subsequence $\left\{y_{n_{i j}}\right\}$ of $\left\{y_{n_{i}}\right\}$ which converges weakly to $q \in C$. Without loss of generality, we can assume that $y_{n_{i}} \rightarrow q$. In similar way, we can obtain $q \in I\left(B, M_{2}\right)$, hence $q \in I\left(A, M_{1}\right) \cap I\left(B, M_{2}\right)$.

Step 8. Finally, we show that $x_{n} \rightarrow z$ and $u_{n} \rightarrow z$, where $z=P_{\Theta} x_{0}$.

Since $\Theta$ is nonempty closed convex subset of $H$, there exists a unique $z^{\prime} \in \Theta$ such that $z^{\prime}=P_{\Theta} x_{0}$. Since $z^{\prime} \in \Theta \subset C_{n}$ and $x_{n}=P_{C_{n}} x_{0}$, we have

$$
\left\|x_{0}-x_{n}\right\| \leq\left\|x_{0}-P_{C_{n}} x_{0}\right\| \leq\left\|x_{0}-z^{\prime}\right\|
$$

for all $n \in \mathbb{N}$. From (3.59) and $\left\{x_{n}\right\}$ is bounded, so $\omega_{w}\left(x_{n}\right) \neq \emptyset$. 
Fixed Point Theory and Applications

By the weakly lower semicontinuous of the norm, we have

$$
\left\|x_{0}-z\right\| \leq \liminf _{n_{i} \rightarrow \infty}\left\|x_{0}-x_{n_{i}}\right\| \leq\left\|x_{0}-z^{\prime}\right\|
$$

However, since $z \in \omega_{w}\left(x_{n}\right) \subset \Theta$, we have

$$
\left\|x_{0}-z^{\prime}\right\| \leq\left\|x_{0}-P_{C_{n}} x_{0}\right\| \leq\left\|x_{0}-z\right\| .
$$

Using (3.59) and (3.60), we obtain $z^{\prime}=z$. Thus $\omega_{w}\left(x_{n}\right)=\{z\}$ and $x_{n} \rightarrow z$. So, we have

$$
\left\|x_{0}-z^{\prime}\right\| \leq\left\|x_{0}-z\right\| \leq \liminf _{n \rightarrow \infty}\left\|x_{0}-x_{n}\right\| \leq \limsup _{n \rightarrow \infty}\left\|x_{0}-x_{n}\right\| \leq\left\|x_{0}-z^{\prime}\right\| .
$$

Thus, we obtain that

$$
\left\|x_{0}-z\right\|=\lim _{n \rightarrow \infty}\left\|x_{0}-x_{n}\right\|=\left\|x_{0}-z^{\prime}\right\|
$$

From $x_{n} \rightarrow z$, we obtain $\left(x_{0}-x_{n}\right) \rightarrow\left(x_{0}-z\right)$. Using the Kadec-Klee property, we obtain that

$$
\left\|x_{n}-z\right\|=\left\|\left(x_{n}-x_{0}\right)-\left(z-x_{0}\right)\right\| \longrightarrow 0 \quad \text { as } n \longrightarrow \infty
$$

and hence $x_{n} \rightarrow z$ in norm. Finally, noticing $\left\|u_{n}-z\right\|=\left\|\Im_{n}^{N} x_{n}-\Im_{n}^{N} z\right\| \leq\left\|x_{n}-z\right\|$. We also conclude that $u_{n} \rightarrow z$ in norm. This completes the proof.

Theorem 3.2. Let $C$ be a nonempty closed convex subset of a real Hilbert space $H$, let $\left\{F_{k}: C \times\right.$ $C \rightarrow \mathcal{R}, k=1,2, \ldots, N\}$ be a finite family of mixed equilibrium functions satisfying conditions (H1)-(H3). Let $\mathcal{S}=\{S(s): 0 \leq s<\infty\}$ be a nonexpansive semigroup on $C$ and let $\left\{t_{n}\right\}$ be a positive real divergent sequence. Let $\left\{V_{i}: C \rightarrow C\right\}_{i=1}^{\infty}$ be a countable family of uniformly $\xi$-strict pseudocontractions, $\left\{T_{i}: C \rightarrow C\right\}_{i=1}^{\infty}$ be the countable family of nonexpansive mappings defined by $T_{i} x=t x+(1-t) V_{i} x$, for all $x \in C$, for all $i \geq 1, t \in[\xi, 1), W_{n}$ be the $W$-mapping defined by (2.8) and $W$ be a mapping defined by (2.9) with $F(W) \neq \emptyset$. Let $A, B: C \rightarrow H$ be $\gamma, \beta$-inverse-strongly monotone mapping. Such that

$$
\Theta:=F(\mathcal{S}) \cap F(W) \cap\left(\bigcap_{k=1}^{N} \operatorname{SMEP}\left(F_{k}\right)\right) \cap \operatorname{VI}(C, A) \cap \operatorname{VI}(C, B) \neq \emptyset .
$$


Let $r_{k}>0, k=1,2, \ldots, N$, which are constants. Let $\left\{x_{n}\right\},\left\{y_{n}\right\},\left\{v_{n}\right\},\left\{z_{n}\right\}$, and $\left\{u_{n}\right\}$ be sequences generated by $x_{0} \in C, C_{1}=C, x_{1}=P_{C_{1}} x_{0}, u_{n} \in C$ and

$$
\begin{gathered}
x_{0}=x \in C \text { chosen arbitrarily, } \\
u_{n}=K_{r_{N, n}}^{F_{N}} K_{r_{N-1, n}}^{F_{N-1}} K_{r_{N-2, n}}^{F_{N-2}} \cdots K_{r_{2, n}}^{F_{2}} K_{r_{1, n}}^{F_{1}} x_{n}, \\
y_{n}=P_{C}\left(u_{n}-\delta_{n} B u_{n}\right), \\
v_{n}=P_{C}\left(y_{n}-\lambda_{n} A y_{n}\right), \\
C_{n+1}=\left\{z \in C_{n}:\left\|z_{n}-z\right\|^{2} \leq\left\|x_{n}-z\right\|^{2}-\alpha_{n}\left(1-\alpha_{n}\right)\left\|v_{n}-\frac{1}{t_{n}} \int_{0}^{t_{n}} S(s) W_{n} v_{n} d s\right\|^{2} \frac{1}{t_{n}} \int_{0}^{t_{n}} S(s) W_{n} v_{n} d s,\right. \\
x_{n+1}=P_{C_{n+1}} x_{0}, \quad n \in \mathbb{N},
\end{gathered}
$$

where $K_{r_{k}}^{F_{k}}: C \rightarrow C, k=1,2, \ldots, N$ is the mapping defined by (2.4) and $\left\{\alpha_{n}\right\}$ be a sequence in $(0,1)$ for all $n \in \mathbb{N}$. Assume the following conditions are satisfied:

(C1) $\eta_{k}: C \times C \rightarrow H$ is $L_{k}$-Lipschitz continuous with constant $k=1,2, \ldots, N$ such that

(a) $\eta_{k}(x, y)+\eta_{k}(y, x)=0$, for all $x, y \in C$,

(b) $x \mapsto \eta_{k}(x, y)$ is affine,

(c) for each fixed $y \in C, y \mapsto \eta_{k}(x, y)$ is sequentially continuous from the weak topology to the weak topology;

(C2) $\mathcal{K}_{k}: C \rightarrow \mathcal{R}$ is $\eta_{k}$-strongly convex with constant $\sigma_{k}>0$ and its derivative $\mathcal{K}_{k}^{\prime}$ is not only sequentially continuous from the weak topology to the strong topology but also Lipschitz continuous with a Lipschitz constant $v_{k}>0$ such that $\sigma_{k}>L_{k} v_{k}$;

(C3) for each $k \in\{1,2, \ldots, N\}$ and for all $x \in C$, there exist a bounded subset $D_{x} \subset C$ and $z_{x} \in C$ such that for any $y \in C \backslash D_{x}$,

$$
F_{k}\left(y, z_{x}\right)+\varphi\left(z_{x}\right)-\varphi(y)+\frac{1}{r_{k}}\left\langle\mathcal{K}^{\prime}(y)-\mathcal{K}^{\prime}(x), \eta\left(z_{x}, y\right)\right\rangle<0,
$$

(C4) $\left\{\alpha_{n}\right\} \subset[c, d]$, for some $c, d \in(\xi, 1)$;

(C5) $\left\{\lambda_{n}\right\} \subset\left[a_{1}, b_{1}\right]$, for some $a_{1}, b_{1} \in(0,2 \gamma]$;

(C6) $\left\{\delta_{n}\right\} \subset\left[a_{2}, b_{2}\right]$, for some $a_{2}, b_{2} \in(0,2 \beta]$;

(C7) $\lim \inf _{n \rightarrow \infty} r_{k, n}>0$, for each $k \in 1,2,3, \ldots, N$.

Then, $\left\{x_{n}\right\}$ and $\left\{u_{n}\right\}$ converge strongly to $z=P_{\Theta} x_{0}$. 
Proof. In Theorem 3.1, take $M_{i}=\varrho_{i C}: H \rightarrow 2^{H}$, where $\rho_{i C}: 0 \rightarrow[0, \infty]$ is the indicator function of $C$, that is,

$$
\rho_{i C}(x)= \begin{cases}0, & x \in C, \\ +\infty, & x \notin C,\end{cases}
$$

for $i=1,2$. Then (1.8) is equivalent to variational inequality problem, that is, to find $\widehat{x} \in C$ such that

$$
\langle A \hat{x}, y-\widehat{x}\rangle \geq 0, \quad \forall y \in C
$$

Again, since $M_{i}=\rho_{i C}$, for $i=1,2$, then

$$
J_{M_{1}, \lambda_{n}}=P_{C}=J_{M_{2}, \delta_{n}} .
$$

So, we have

$$
\begin{gathered}
v_{n}=P_{C}\left(y_{n}-\lambda_{n} A y_{n}\right)=J_{M_{1}, \lambda_{n}}\left(y_{n}-\lambda_{n} A y_{n}\right), \\
y_{n}=P_{C}\left(u_{n}-\delta_{n} B u_{n}\right)=J_{M_{2}, \delta_{n}}\left(u_{n}-\delta_{n} B u_{n}\right) .
\end{gathered}
$$

Hence, we can obtain the desired conclusion from Theorem 3.1 immediately.

Next, we consider another class of important mappings.

Definition 3.3. A mapping $S: C \rightarrow C$ is called strictly pseudocontraction if there exists a constant $0 \leq \kappa<1$ such that

$$
\|S x-S y\|^{2} \leq\|x-y\|^{2}+\kappa\|(I-S) x-(I-S) y\|^{2}, \quad \forall x, y \in C
$$

If $\kappa=0$, then $S$ is nonexpansive. In this case, we say that $S: C \rightarrow C$ is a $\kappa$-strictly pseudocontraction. Putting $B=I-S$. Then, we have

$$
\|(I-B) x-(I-B) y\|^{2} \leq\|x-y\|^{2}+\kappa\|B x-B y\|^{2}, \quad \forall x, y \in C .
$$

Observe that

$$
\|(I-B) x-(I-B) y\|^{2}=\|x-y\|^{2}+\|B x-B y\|^{2}-2\langle x-y, B x-B y\rangle, \quad \forall x, y \in C .
$$

Hence, we obtain

$$
\langle x-y, B x-B y\rangle \geq \frac{1-\kappa}{2}\|B x-B y\|^{2}, \quad \forall x, y \in C .
$$

Then, $B$ is $(1-\kappa) / 2$-inverse-strongly monotone mapping. 
Now, we obtain the following result.

Theorem 3.4. Let $C$ be a nonempty closed convex subset of a real Hilbert space $H$, let $\left\{F_{k}: C \times\right.$ $C \rightarrow R, k=1,2, \ldots, N\}$ be a finite family of mixed equilibrium functions satisfying conditions (H1)-(H3). Let $S=\{S(s): 0 \leq s<\infty\}$ be a nonexpansive semigroup on $C$ and let $\left\{t_{n}\right\}$ be a positive real divergent sequence. Let $\left\{V_{i}: C \rightarrow C\right\}_{i=1}^{\infty}$ be a countable family of uniformly $\xi$-strict pseudocontractions, $\left\{T_{i}: C \rightarrow C\right\}_{i=1}^{\infty}$ be the countable family of nonexpansive mappings defined by $T_{i} x=t x+(1-t) V_{i} x$, for all $x \in C$, for all $i \geq 1, t \in[\xi, 1), W_{n}$ be the $W$-mapping defined by (2.8) and $W$ be a mapping defined by (2.9) with $F(W) \neq \emptyset$. Let $A, B: C \rightarrow H$ be $\gamma, \beta$-inverse-strongly monotone mapping and $S_{A}, S_{B}$ be $\kappa_{\gamma}, \kappa_{\beta}$-strictly pseudocontraction mapping of $C$ into $C$ for some $0 \leq \kappa_{\gamma}<1,0 \leq \kappa_{\beta}<1$ such that

$$
\Theta:=F(\mathcal{S}) \cap F(W) \cap\left(\bigcap_{k=1}^{N} \operatorname{SMEP}\left(F_{k}\right)\right) \cap F\left(S_{A}\right) \cap F\left(S_{B}\right) \neq \emptyset .
$$

Let $r_{k}>0, k=1,2, \ldots, N$, which are constants. Let $\left\{x_{n}\right\},\left\{y_{n}\right\},\left\{v_{n}\right\},\left\{z_{n}\right\}$, and $\left\{u_{n}\right\}$ be sequences generated by $x_{0} \in C, C_{1}=C, x_{1}=P_{C_{1}} x_{0}, u_{n} \in C$ and

$$
\begin{gathered}
x_{0}=x \in C \text { chosen arbitrarily, } \\
u_{n}=K_{r_{N, n}}^{F_{N}} K_{r_{N-1, n}}^{F_{N-1}} K_{r_{N-2, n}}^{F_{N-2}} \cdots K_{r_{2, n}}^{F_{2}} K_{r_{1, n}}^{F_{1}} x_{n}, \\
y_{n}=\left(1-\delta_{n}\right) u_{n}+\delta_{n} S_{B} u_{n} \\
v_{n}=\left(1-\lambda_{n}\right) y_{n}+\lambda_{n} S_{A} y_{n}, \\
z_{n}=\alpha_{n} v_{n}+\left(1-\alpha_{n}\right) \frac{1}{t_{n}} \int_{0}^{t_{n}} S(s) W_{n} v_{n} d s, \\
C_{n+1}=\left\{z \in C_{n}:\left\|z_{n}-z\right\|^{2} \leq\left\|x_{n}-z\right\|^{2}-\alpha_{n}\left(1-\alpha_{n}\right)\left\|v_{n}-\frac{1}{t_{n}} \int_{0}^{t_{n}} S(s) W_{n} v_{n} d s\right\|^{2}\right\}, \\
x_{n+1}=P_{C_{n+1}} x_{0}, \quad n \in \mathbb{N},
\end{gathered}
$$

where $K_{r_{k}}^{F_{k}}: C \rightarrow C, k=1,2, \ldots, N$ is the mapping defined by (2.4) and $\left\{\alpha_{n}\right\}$ be a sequence in $(0,1)$ for all $n \in \mathbb{N}$. Assume the following conditions are satisfied:

(C1) $\eta_{k}: C \times C \rightarrow H$ is $L_{k}$-Lipschitz continuous with constant $k=1,2, \ldots, N$ such that

(a) $\eta_{k}(x, y)+\eta_{k}(y, x)=0$, for all $x, y \in C$,

(b) $x \mapsto \eta_{k}(x, y)$ is affine,

(c) for each fixed $y \in C, y \mapsto \eta_{k}(x, y)$ is sequentially continuous from the weak topology to the weak topology;

(C2) $\mathcal{K}_{k}: C \rightarrow \mathcal{R}$ is $\eta_{k}$-strongly convex with constant $\sigma_{k}>0$ and its derivative $\mathcal{K}_{k}^{\prime}$ is not only sequentially continuous from the weak topology to the strong topology but also Lipschitz continuous with a Lipschitz constant $v_{k}>0$ such that $\sigma_{k}>L_{k} v_{k}$; 
(C3) for each $k \in\{1,2, \ldots, N\}$ and for all $x \in C$, there exist a bounded subset $D_{x} \subset C$ and $z_{x} \in C$ such that for any $y \in C \backslash D_{x}$

$$
F_{k}\left(y, z_{x}\right)+\varphi\left(z_{x}\right)-\varphi(y)+\frac{1}{r_{k}}\left\langle\mathcal{K}^{\prime}(y)-\mathcal{K}^{\prime}(x), \eta\left(z_{x}, y\right)\right\rangle<0
$$

(C4) $\left\{\alpha_{n}\right\} \subset[c, d]$, for some $c, d \in(\xi, 1)$;

(C5) $\left\{\lambda_{n}\right\} \subset\left[a_{1}, b_{1}\right]$, for some $a_{1}, b_{1} \in(0,2 \gamma]$;

(C6) $\left\{\delta_{n}\right\} \subset\left[a_{2}, b_{2}\right]$, for some $a_{2}, b_{2} \in(0,2 \beta]$;

(C7) $\lim \inf _{n \rightarrow \infty} r_{k, n}>0$, for each $k \in 1,2,3, \ldots, N$

Then, $\left\{x_{n}\right\}$ and $\left\{u_{n}\right\}$ converge strongly to $z=P_{\Theta} x_{0}$.

Proof. Taking $A \equiv I-S_{A}$ and $B \equiv I-S_{B}$, then we see that $A, B$ is $\left(1-\kappa_{\gamma}\right) / 2,\left(1-\kappa_{\beta}\right) / 2$-inversestrongly monotone mapping, respectively. We have $F\left(S_{A}\right)=\mathrm{VI}(C, A)$ and $F\left(S_{B}\right)=\mathrm{VI}(C, B)$. So, we have

$$
\begin{gathered}
y_{n}=P_{C}\left(u_{n}-\delta_{n} B u_{n}\right)=P_{C}\left(\left(1-\delta_{n}\right) u_{n}+\delta_{n} S_{B} u_{n}\right)=\left(1-\delta_{n}\right) u_{n}+\delta_{n} S_{B} u_{n} \in C \\
v_{n}=P_{C}\left(y_{n}-\lambda_{n} A y_{n}\right)=P_{C}\left(\left(1-\lambda_{n}\right) y_{n}+\lambda_{n} S_{A} y_{n}\right)=\left(1-\lambda_{n}\right) y_{n}+\lambda_{n} S_{A} y_{n} \in C
\end{gathered}
$$

By using Theorem 3.2, it is easy to obtain the desired conclusion.

\section{Acknowledgments}

The authors would like to thank the Faculty of Science, King Monkut's University of Technology Thonburi for its financial support. Moreover, P. Kumam was supported by the Commission on Higher Education and the Thailand Research Fund under Grant MRG5380044.

\section{References}

[1] F. Flores-Bazán, "Existence theorems for generalized noncoercive equilibrium problems: the quasiconvex case," SIAM Journal on Optimization, vol. 11, no. 3, pp. 675-690, 2000.

[2] P. L. Combettes and S. A. Hirstoaga, "Equilibrium programming in Hilbert spaces," Journal of Nonlinear and Convex Analysis, vol. 6, no. 1, pp. 117-136, 2005.

[3] E. Blum and W. Oettli, "From optimization and variational inequalities to equilibrium problems," The Mathematics Student, vol. 63, no. 1-4, pp. 123-145, 1994.

[4] O. Chadli, N. C. Wong, and J. C. Yao, "Equilibrium problems with applications to eigenvalue problems," Journal of Optimization Theory and Applications, vol. 117, no. 2, pp. 245-266, 2003.

[5] O. Chadli, S. Schaible, and J. C. Yao, "Regularized equilibrium problems with application to noncoercive hemivariational inequalities," Journal of Optimization Theory and Applications, vol. 121, no. 3, pp. 571-596, 2004.

[6] I. V. Konnov, S. Schaible, and J. C. Yao, "Combined relaxation method for mixed equilibrium problems," Journal of Optimization Theory and Applications, vol. 126, no. 2, pp. 309-322, 2005.

[7] A. Moudafi and M. Théra, "Proximal and dynamical approaches to equilibrium problems," in Lecture Notes in Econcmics and Mathematical Systems, vol. 477, pp. 187-201, Springer, Berlin, Germany, 1999.

[8] L.-C. Zeng, S.-Y. Wu, and J.-C. Yao, "Generalized KKM theorem with applications to generalized minimax inequalities and generalized equilibrium problems," Taiwanese Journal of Mathematics, vol. 10, no. 6, pp. 1497-1514, 2006. 
[9] T. Jitpeera and P. Kumam, "An extra gradient type method for a system of equilibrium problems, variational inequality problems and fixed points of finitely many nonexpansive mappings," Journal of Nonlinear Analysis and Optimization: Theory E Applications, vol. 1, no. 1, pp. 71-91, 2010.

[10] F. Cianciaruso, G. Marino, L. Muglia, and Y. Yao, "A hybrid projection algorithm for finding solutions of mixed equilibrium problem and variational inequality problem," Fixed Point Theory and Applications, vol. 2010, Article ID 383740, 19 pages, 2010.

[11] P. Cholamjiak and S. Suantai, "A new hybrid algorithm for variational inclusions, generalized equilibrium problems, and a finite family of quasi-nonexpansive mappings," Fixed Point Theory and Applications, vol. 2009, Article ID 350979, 20 pages, 2009.

[12] C. Jaiboon and P. Kumam, "Strong convergence for generalized equilibrium problems, fixed point problems and relaxed cocoercive variational inequalities," Journal of Inequalities and Applications, vol. 2010, Article ID 728028, 43 pages, 2010.

[13] C. Jaiboon, W. Chantarangsi, and P. Kumam, "A convergence theorem based on a hybrid relaxed extragradient method for generalized equilibrium problems and fixed point problems of a finite family of nonexpansive mappings," Nonlinear Analysis. Hybrid Systems, vol. 4, no. 1, pp. 199-215, 2010.

[14] P. Kumam and C. Jaiboon, "A new hybrid iterative method for mixed equilibrium problems and variational inequality problem for relaxed cocoercive mappings with application to optimization problems," Nonlinear Analysis. Hybrid Systems, vol. 3, no. 4, pp. 510-530, 2009.

[15] Y. Shehu, "Fixed point solutions of variational inequality and generalized equilibrium problems with applications," Annali dell'Universita di Ferrara, vol. 56, no. 2, pp. 345-368, 2010.

[16] Y. Yao, Y.-C. Liou, and J.-C. Yao, "A new hybrid iterative algorithm for fixed-point problems, variational inequality problems, and mixed equilibrium problems," Fixed Point Theory and Applications, vol. 2008, Article ID 417089, 15 pages, 2008.

[17] Y. Yao, Y.-C. Liou, and Y.-J. Wu, "An extragradient method for mixed equilibrium problems and fixed point problems," Fixed Point Theory and Applications, vol. 2009, Article ID 632819, 15 pages, 2009.

[18] Y. Hao, "On variational inclusion and common fixed point problems in Hilbert spaces with applications," Applied Mathematics and Computation, vol. 217, no. 7, pp. 3000-3010, 2010.

[19] Q. H. Ansari and J. C. Yao, “Iterative schemes for solving mixed variational-like inequalities," Journal of Optimization Theory and Applications, vol. 108, no. 3, pp. 527-541, 2001.

[20] H. Brézis, "Opérateur maximaux monotones," in Mathematics Studies, vol. 5, North-Holland, Amsterdam, The Netherlands, 1973.

[21] B. Lemaire, "Which fixed point does the iteration method select?" in Recent Advances in Optimization, vol. 452 of Lecture Notes in Economics and Mathematical Systems, pp. 154-167, Springer, Berlin, Germany, 1997.

[22] W. Takahashi, Y. Takeuchi, and R. Kubota, "Strong convergence theorems by hybrid methods for families of nonexpansive mappings in Hilbert spaces," Journal of Mathematical Analysis and Applications, vol. 341, no. 1, pp. 276-286, 2008.

[23] S. Takahashi and W. Takahashi, "Strong convergence theorem for a generalized equilibrium problem and a nonexpansive mapping in a Hilbert space," Nonlinear Analysis. Theory, Methods $\mathcal{E}$ Applications, vol. 69, no. 3, pp. 1025-1033, 2008.

[24] S.-S. Zhang, J. H. W. Lee, and C. K. Chan, "Algorithms of common solutions to quasi variational inclusion and fixed point problems," Applied Mathematics and Mechanics. English Edition, vol. 29, no. 5, pp. 571-581, 2008.

[25] J.-W. Peng, Y. Wang, D. S. Shyu, and J.-C. Yao, "Common solutions of an iterative scheme for variational inclusions, equilibrium problems, and fixed point problems," Journal of Inequalities and Applications, vol. 2008, Article ID 720371, 15 pages, 2008.

[26] S. Saeidi, "Iterative algorithms for finding common solutions of variational inequalities and systems of equilibrium problems and fixed points of families and semigroups of nonexpansive mappings," Nonlinear Analysis. Theory, Methods E Applications, vol. 70, no. 12, pp. 4195-4208, 2009.

[27] P. Katchang and P. Kumam, "A general iterative method of fixed points for mixed equilibrium problems and variational inclusion problems," Journal of Inequalities and Applications, vol. 2010, Article ID 370197, 25 pages, 2010.

[28] W. Kumam, C. Jaiboon, P. Kumam, and A. Singta, "A shrinking projection method for generalized mixed equilibrium problems, variational inclusion problems and a finite family of quasinonexpansive mappings," Journal of Inequalities and Applications, vol. 2010, Article ID 458247, 25 pages, 2010. 
[29] M. Liu, S. S. Chang, and P. Zuo, "An algorithm for finding a common solution for a system of mixed equilibrium problem, quasivariational inclusion problem, and fixed point problem of nonexpansive semigroup," Journal of Inequalities and Applications, vol. 2010, Article ID 895907, 23 pages, 2010.

[30] T. Jitpeera and P. Kumam, "A new hybrid algorithm for a system ofequilibrium problems and variational inclusion," Annali dell'Universita di Ferrara. In press.

[31] G. L. Acedo and H.-K. Xu, "Iterative methods for strict pseudo-contractions in Hilbert spaces," Nonlinear Analysis. Theory, Methods \& Applications, vol. 67, no. 7, pp. 2258-2271, 2007.

[32] Z. Opial, "Weak convergence of the sequence of successive approximations for nonexpansive mappings," Bulletin of the American Mathematical Society, vol. 73, pp. 591-597, 1967.

[33] W. Takahashi, Nonlinear Functional Analysis, Yokohama Publishers, Yokohama, Japan, 2000.

[34] L.-C. Ceng and J.-C. Yao, "A hybrid iterative scheme for mixed equilibrium problems and fixed point problems," Journal of Computational and Applied Mathematics, vol. 214, no. 1, pp. 186-201, 2008.

[35] Haiyun Zhou, "Convergence theorems of fixed points for $\kappa$-strict pseudo-contractions in Hilbert spaces," Nonlinear Analysis. Theory, Methods \& Applications, vol. 69, no. 2, pp. 456-462, 2008.

[36] K. Shimoji and W. Takahashi, "Strong convergence to common fixed points of infinite nonexpansive mappings and applications," Taiwanese Journal of Mathematics, vol. 5, no. 2, pp. 387-404, 2001.

[37] S. S. Chang, Variational Inequalities and Related Problems, Chongqing Publishing House, China, 2007.

[38] T. Shimizu and W. Takahashi, "Strong convergence to common fixed points of families of nonexpansive mappings," Journal of Mathematical Analysis and Applications, vol. 211, no. 1, pp. 71-83, 1997.

[39] K.-K. Tan and H. K. Xu, "The nonlinear ergodic theorem for asymptotically nonexpansive mappings in Banach spaces," Proceedings of the American Mathematical Society, vol. 114, no. 2, pp. 399-404, 1992. 